\title{
Demographic and socioeconomic characteristics of outpatients could modify their attitude towards misusing medications in northern Jordan
}

\author{
Mansour Haddad, ${ }^{1}$ Mohamed Elsaed Ebada ${ }^{2}$ \\ ${ }^{1}$ Department of Clinical Sciences, Faculty of Pharmacy, Philadelphia University, Amman, Jordan; \\ ${ }^{2}$ Department of Pharmacology, National Organization for Drug Control and Research (NODCAR), \\ Agouza, Giza, Egypt
}

Significance for public health

Evaluating and reducing potentially inappropriate drug use are two important approaches towards improving the therapeutic outcome and patient compliance. It is speculated that the prevalence of inappropriate drug use among hospitalised patients is relatively low providing that healthcare and direct observation by professional staff limit its incidence. On the other hand, outpatients seem to be the most sufferers from misusing prescribed and non-prescribed drugs and therefore clearly informing them about the dispensed medications especially by the community/hospital pharmacists could probably encourage them to follow the standard and approved instructions to avoid negative consequences. This survey also points out that patients could play a role in developing better health policies and improved health services by assessing their habits and compliance with regard to the use of prescribed and over-the-counter medications.

\section{Abstract}

Background. Potentially inappropriate drug use, including prescribed and over-the-counter medications, is associated with increased morbidity and mortality. It also contributes to unnecessary expenditure on health services. This survey was undertaken to investigate the incidence of drug misuse and associated socioeconomic/demographic characteristics in Irbid, Jordan.

Design and Methods. The present cross section study was conducted using a validated 5-point Likert scale questionnaire to be self-reported by 480 outpatients visiting clinics in three major medical centres in Irbid, Jordan between 20th October 2015 and 27th November 2015. Descriptive analysis, chi-square tests and ordinal logistic regression models were performed.

Results. Patients demonstrated distinctive attitudes towards medication misuse $(\mathrm{P}<0.001)$. Whereas around $40 \%$ of patients sometimes stopped taking medications earlier than prescribed or doubled the dose in case of missing a dose, three quarters and two fifth of participants neither used expired drugs nor continued to take a drug when adverse drug reactions occurred, respectively. Also, there were significant associations $(\mathrm{P}<0.05)$ between patients' attitudes towards misusing medications and characteristics like age, gender, income and marital status. For instance, senior patients ( $>45$ years) tended to double a medication's dose in case of no improvement, and to use others' leftover drugs without medical supervision. Further, male and female patients exhibited different attitude towards misusing medications. Unemployment and little earnings increased the risk for not using drugs properly. Furthermore, married patients were less likely to misuse medications. In particular, the educational level of patients was found to play a major role in modifying patients' attitudes towards potentially inappropriate drug use. Patients holding one or more university degrees were at lower risk for using medications inappropriately.

Conclusions. This survey indicated that northern Jordanians inappropriately used medications to a great extent, suggesting that the current policies should be revised, and emphasising the importance of running public antidrug misuse awareness campaigns and establishing advanced educational/training events targeting healthcare professionals.

\section{Introduction}

It has been debated that inappropriate drug use (IDU) could contribute to the increased risk of morbidity and mortality in certain population and to the marked rise in the rates of hospital admission, imposing a significant financial burden. ${ }^{1}$ IDU could be identified when the risk outweighs benefit. ${ }^{2}$ Alternatively, IDU could be avoided by monitoring the appropriateness of the prescribed treatment. This includes but not limited to the right selection of drugs to be taken in combination, recommended doses, possible drug-drug interactions and drug-disease interactions in certain individuals. Besides, uncontrolled use of over-the-counter drugs and herbal supplements is a leading cause of IDU, ${ }^{3,4}$ raising the need for establishing various effective strategies to increase awareness of patients about IDU especially with non-prescribed drugs. Although IDU is reported to impact all people, there has been high incidence of medication misuse in the elderly. ${ }^{2}$ This could be due to the fact that senior patients usually suffer from several diseases necessitating the use of multiple medications. 5,6 Paediatric patients are also considered another vulnerable group because of the underdeveloped drug metabolizing system and therefore accurate doses based on body weight should only be prescribed to avoid serious adverse drug effects and possible toxicity. ${ }^{7}$ IDU increases the frequency of hospital admission and is a major risk factor for drug-related morbidity. ${ }^{8}$ Indeed, it could be expected that IDU negatively affects one's health as well as the use of healthcare services. It is sometimes difficult to distinguish between IDU and the standard use of medications, particularly for geriatric patients. ${ }^{2}$ Therefore, several criteria, ${ }^{9}$ such as Beers' criteria, ${ }^{10}$ have been developed and continuously updated to control IDU in senior patients. Beers' criteria is an explicit criteria established for the purpose of monitoring and improving the safety of using certain drugs in the elderly. ${ }^{11,12}$ It has been widely accepted that the responsibility for the proper use of medications is divided between patients, physicians, pharmacists and nurses. ${ }^{13-15}$ Eventually, IDU is a com- 
plex issue which should be monitored and regulated through implementing a number of policies which need continuous modifications and efficient contribution from all members of healthcare providers in order to establish updated effective procedures and criteria to cope with different features of IDU and its consequences on patients' health and compliance. ${ }^{8,16,17}$ The present study was carried out to investigate to what extent IDU could be prevalent among outpatients in Irbid, Jordan and whether there would be an association between the relative risk for IDU and demographic/socioeconomic characteristics of patients.

\section{Design and Methods}

\section{Population}

Patients $(n=480)$ routinely visiting any of three randomly selected medical centres, namely Areen Medical Centre, Dahiyat AlHussein Health Centre and Princess Basma Teaching Hospital in Irbid, Jordan, were enrolled in the present survey, over approximately 5 weeks, between 20th October 2015 and 27th November 2015. Participants were categorised according to their demographic and socioeconomic characteristics including gender, age, income, education, urban/rural home and marital status. The study was approved by the ethical research committee of Philadelphia University Faculty of Pharmacy, Amman, Jordan.

\section{Questionnaire}

A self-reported pre-validated questionnaire was made available to be completed by outpatients. Briefly, outpatients were invited at the reception of the clinics to fill the questionnaire and if they agreed to do so, a short interview was conducted with temporary hired staff (postgraduate students) in a meeting room on site to inform them about the purpose of the study and the questionnaire's content. Afterwards, participants were asked to fill the questionnaire in another adjacent room over a 30-minute period after signing a consent form as a requirement to participate in the survey. A support was especially provided to illiterate patients or those with limited educational level to complete the questionnaire. The questionnaire's validation was undertaken over 2 steps. Firstly, some questions were obtained and amended from the literature, ${ }^{7,14}$ others were developed to study the different attitudes of a wide variety of people misusing medications. Secondly, a pilot study had been carried out on a small number $(n=30)$ of outpatients who were asked to fill the preliminary questionnaire and the selected questions which had Cronbach's Alpha coefficient, which reflects on the reliability of the questionnaires, ${ }^{18,19}$ of 0.75 were approved to be in the questionnaire. The questionnaire consisted of two parts. The first part was dedicated for collecting demographic and socioeconomic data. The second part contained 20 Likert scaled questions, in which the possible answers are ranked on a 5-7 point scale providing that the first and last points are opposites (i.e. always and never, strongly agree and strongly disagree) and this is considered an effective approach to study people's attitudes towards various situations. ${ }^{20}$ Questions were responded with one of five answers in order: always, often, sometimes, rarely, never.

\section{Statistical analysis}

The completed questionnaires were coded and the data were analysed using the IBM SPSS Package Version 19. Data were descriptively analysed and chi-square tests were performed to examine whether data were equally distributed amongst the five answers (goodness of fit), and to test whether patients' answers were independent of their demographic and socioeconomic characteristics.
Fisher's Exact tests were alternatively used to test the independence as appropriate. The ordinal logistic regression models, especially effective with ordinal data (i.e. the Likert scaled questions), were undertaken to study the impact of demographic/socioeconomic characteristics (independent variables, merged to be 2 categories/levels for each characteristic) including gender (male vs female), age (patients aged less than or 45 years $v s$ others aged more than 45 years), income (subjects earning 240 Jordanian dinars monthly at maximum $v s$ others earning higher salary), education (no university education $v s$ university graduates), home (urban $v s$ rural) and marital status (married $v s$ unmarried) on the response to questions (dependent variables, with 5 levels/answers, always, often, sometimes, rarely and never), thereby calculating the odds ratios and confidence intervals at $95 \%$. Significance was reached when $\mathrm{P}<0.05$.

\section{Results}

\section{Descriptive analysis}

Participants were categorised according to gender, age, income, level of education, home and marital status (please see Table 1 for all details).

Table 1. Demographic and socioeconomic characteristics of outpatients $(n=480)$.

\begin{tabular}{|c|c|c|}
\hline 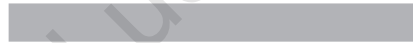 & N. & $\%$ \\
\hline $\begin{array}{l}\text { Gender } \\
\text { Male } \\
\text { Female }\end{array}$ & $\begin{array}{l}240 \\
240\end{array}$ & $\begin{array}{l}50 \\
50\end{array}$ \\
\hline 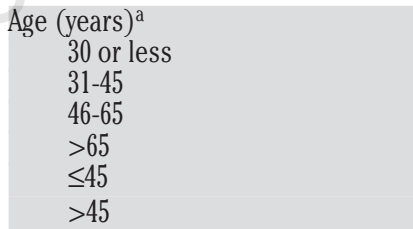 & $\begin{array}{c}162 \\
177 \\
129 \\
12 \\
339 \\
141\end{array}$ & $\begin{array}{c}33.75 \\
36.88 \\
26.88 \\
2.5 \\
70.63 \\
29.37\end{array}$ \\
\hline $\begin{array}{l}\text { Home } \\
\text { Irbid^}^{\wedge} \\
\text { Amman }^{\wedge} \\
\text { Village }^{\$} \\
\text { Desert }^{\$} \\
\text { Urban } \\
\text { Rural }\end{array}$ & $\begin{array}{c}390 \\
21 \\
69 \\
0 \\
411 \\
69\end{array}$ & $\begin{array}{c}81.25 \\
4.38 \\
14.38 \\
0 \\
85.63 \\
14.37\end{array}$ \\
\hline $\begin{array}{l}\text { Education } \\
\text { Illiterate } \\
\text { Primary/Preparatory school } \\
\text { High School } \\
\text { University degree (Bachelor) } \\
\text { Postgraduate degree (i.e. PhD) } \\
\text { Pre-university education } \\
\text { University degree(s) }\end{array}$ & $\begin{array}{c}6 \\
80 \\
104 \\
245 \\
45 \\
190 \\
290\end{array}$ & $\begin{array}{c}1.25 \\
16.67 \\
21.67 \\
51.04 \\
9.38 \\
39.58 \\
60.42\end{array}$ \\
\hline $\begin{array}{l}\text { Marital status } \\
\text { Married } \\
\text { Unmarried } \\
\text { Single } \\
\text { Divorced } \\
\text { Widow }\end{array}$ & $\begin{array}{c}262 \\
218 \\
171 \\
25 \\
22\end{array}$ & $\begin{array}{c}54.58 \\
45.42 \\
35.63 \\
5.21 \\
4.58\end{array}$ \\
\hline $\begin{array}{l}\text { Income }{ }^{\mathrm{b}, \mathrm{c}} \\
\quad \text { Unemployed } \\
\quad \leq 240 \text { JD (poor class) }{ }^{\mathrm{d}} \\
\text { >240 JD (middle class) }\end{array}$ & $\begin{array}{c}57 \\
253 \\
227\end{array}$ & $\begin{array}{l}11.88 \\
52.71 \\
47.29\end{array}$ \\
\hline
\end{tabular}


The results revealed that patients misused medications to a great extent. The chi-square test (goodness of fit) detected that no equal distribution/frequency was found between the five answers of all questions $(\mathrm{P}<0.001)$, reflecting different attitudes of patients towards the proper use of medications. The percentages of each answer to total per question, median and interquartile range are listed in Table 2.

A significant number of patients inappropriately used the prescribed or over-the-counter drugs. For example, almost 2 fifth of the participants sometimes stopped taking the drugs earlier than recommended or avoided to purchase expensive prescribed medications. In addition, $41.9 \%$ of patients rarely/never consulted the physician in case of repurchasing prescribed medications. Also, about one sixth of patients rarely/never had regular physical examinations even if they had to use their medications for a long time, and $13.4 \%$ always/often used to repeat purchasing drugs without consulting the physician. Additionally, about one fifth of patients rarely/never referred to the new instructions about the standard use of previously dispensed medications for the treatment of another illness. In case of forgetting how to use a medication, $25 \%$ of patients were always more willing to seek advice from the pharmacist than from the physician. On the other hand, approximately $5 \%$ of patients claimed that the physician rarely/never asked them about currently used medications. It is important to point out that the middle answer sometimes came first on questions involving the administration of double doses in case of no improvement or missing a scheduled dose. However, some responses indicated that considerably high percentages of patients were taking a proactive approach against IDU. For instance, $39.8 \%$ of patients rarely gave advice or shared experience with others with regard to the use of drugs, and 1 in 3 patients never donated their leftover drugs to others to use. Moreover, three quarters of all respondents never used any medications when expired, and slightly above half of patients rarely/never took any drugs without consulting the physician or the pharmacist. Furthermore, it had not happened to about $40 \%$ of participants to continue taking medications if their adverse effects occurred.

\section{The association between patients' attitudes and their characteristics}

Chi-square and Fisher's Exact tests demonstrated that responses of patients to the questionnaire were not independent of their demographic and socioeconomic characteristics (Table 3 ). It seems interesting that the level of education was found to be influencing the answers to 12 out of 20 questions. In contrast, home conditions showed associations with answers to only one question Do you repeat purchasing a drug without consulting the physician? On the other hand, marital status had significant impact on the responses to 3 questions like doubling the dose if patients did not feel improved, stopping drug taking suddenly and whether they had regular physical examinations in case of taking medications for chronic diseases. Expectedly, marked association was detected between monthly salaries and levels of education and avoiding the purchase of expensive prescribed medications. Also, the motivation to read the standard instructions in order to know how to use the dispensed medications was substantially linked to gender, age and educational level. There were also gender related impacts on the use of expired medications and the increased amount of drug taken if a dose was missed and the provision of advice on using medications to others. It is worth noting that there were no associations between patients' characteristics and the response to questions asking about seeking advice from the pharmacist or the physician about the use of medications in case of uncertainty. On the contrary, answers to the question regarding the sudden cessation of drug therapy were found to be influenced by 4 characteristics, gender, income, education and marital status.

\section{Demographic and socioeconomic characteristics of patients modi- fied their attitudes towards inappropriate drug use}

Ordinal logistic regression models were undertaken to address to what extent patients' characteristics modified their attitudes towards medication misuse. The Logistic regression was performed to calculate odds ratios and confidence intervals at $95 \%$ (Table 4). It is important to note that all independent variables (patients' characteristics) were categories, 2 levels each, gender (male $v s$ female), age (patients aged less than or equal to 45 years $v s$ others aged more than 45 years), income (patients earning $\leq 240$ JD per month $v s$ others earning more than $240 \mathrm{JD}$ ), education (no university education $v s$ university graduates), home (urban areas residents $v s$ rural areas residents), marital status (married $v s$ unmarried), the second level of each independent variable was set as a reference. Dependent variables/answers to questions (a 5-point Likert scale) were ranked as follows: always (1), often (2), sometimes (3), rarely (4) and never (5). The last answer never was set as a reference. Overall university education seems to play a major protective role against the vulnerability to use medications inappropriately. In fact, odds ratios were found to be significant between responses to 13 questions and the educational level. Generally, it is critical to refer to each question to clearly interpret why odds ratios could be $<1$ with some questions or $>1$ with other questions and indicate high risk for medications misuse in all cases. For example, the odds of patients with no university education was $53 \%$ (i.e. 1-0.47) lower than university graduates' in willing to purchase expensive prescribed drugs. Also, the odds of patients with high school education at maximum was $38 \%$ lower than that of patients holding one or more university degrees in not doubling the amount of a drug to be taken in case of missing a dose. Moreover, the odds of participants who had no university degree were $88 \%$ higher than odds of university graduates in not reading the instructions about the medication use. Also, answers to 3 out of 5 questions indicated that male patients exhibited more positive attitude than females towards IDU. In contrast, the odds of male participants were 2.46 times that of female patients in not reading the instructions about using their medications. Also, male participants were more likely to use expired drugs compared to females (odds ratio $=0.56$ ). Obviously, patients who earned less than or equal to 240 Jordanian dinars per month were at risk for using drugs inappropriately. This could be inferred from Table 4 showing that odds ratios of poor class patients were $<1$ for stopping drug treatment suddenly or avoiding the purchase of expensive drugs compared to higher salary patients. With regard to the effects of age, patients older than 45 years exhibited higher tendency to misuse medications. To make it clear, the odds of young patients was 1.51 times that of senior patients in not using others' leftover drugs. Moreover, young patients were less likely to double the dose in case of no improvement (odds ratio $=1.94$ ), and were more willing to purchase medications even if expensive (odds ratio $=1.60)$. On the other side, older patients were more keen to have regular physical examination than young patients in case of using medications on a chronic basis (odd ratio $=1.55$ ).

Interestingly, responses to 8 out of 10 questions with significant odds ratios demonstrated that married patients had low incidence of IDU compared to unmarried patients. An important point was that no significant impact of all patients' characteristics on their tendency to seek the advice from the physician to ensure that medications were used correctly, and on their motivation to tell the physician about currently used drugs upon consultation was detect- 
Table 2. Questionnaire filled by outpatients and the percentage of each possible answer.

\begin{tabular}{|c|c|c|c|c|c|c|c|}
\hline \multirow{2}{*}{\multicolumn{2}{|c|}{ Questions $^{\mathrm{a}}$}} & \multicolumn{5}{|c|}{ Answers* (\% to total) } & \multirow{2}{*}{$\begin{array}{c}\text { Median } \\
\text { (IQR) }\end{array}$} \\
\hline & & 1 & 2 & 3 & 4 & 5 & \\
\hline 1 & Have you ever avoided purchasing the prescribed medication solely due to high cost? & 5.2 & 12.1 & 39.2 & 19.8 & 23.8 & $3(1)$ \\
\hline 2 & Do you abruptly stop taking your medication earlier than prescribed? & 2.5 & 8.5 & 39.4 & 33.3 & 16.3 & $3(1)$ \\
\hline 3 & Do you take into consideration the exact time of administering your medications? & 41.7 & 45.6 & 10.0 & 1.9 & 0.8 & $2(1)$ \\
\hline 4 & Do you take into consideration the conditions of administering a drug i.e. before/after meals? & 40 & 47.3 & 10.2 & 0.6 & 1.9 & $2(1)$ \\
\hline 5 & Do you double the dose if you forget lor 2 doses? & 1.5 & 5.0 & 39.0 & 24.2 & 30.4 & $4(2)$ \\
\hline 6 & Do you double the dose if you do not feel better? & 1.5 & 5.0 & 31.9 & 31.7 & 30.0 & $4(2)$ \\
\hline 7 & Do you use any medication without consulting your physician or pharmacist? & 2.9 & 7.3 & 34.0 & 35.0 & 20.8 & $4(1)$ \\
\hline 8 & Do you use others' leftover drugs? & 0.6 & 6.3 & 29.0 & 31.9 & 32.3 & $4(2)$ \\
\hline 9 & Do you donate your medications if someone needs them? & 2.3 & 7.5 & 25.6 & 31.0 & 33.5 & $4(2)$ \\
\hline 10 & Do you advise the others to use any drugs without medical examination? & 0.8 & 6.7 & 22.1 & 39.8 & 30.6 & $4(2)$ \\
\hline 11 & Do you continue taking a drug after its expiry date is reached? & 0.2 & 0.4 & 2.3 & 22.1 & 75.0 & $5(0.75)$ \\
\hline 12 & Do you continue taking a drug even if side effects occur? & 0.6 & 5.4 & 16.5 & 37.3 & 40.2 & $4(1)$ \\
\hline 13 & Do you have regular physical examinations if you have to use any drug for a long time? & 30.0 & 29.6 & 22.5 & 10.8 & 7.1 & $2(2)$ \\
\hline 14 & Do you repeat purchasing a drug without consulting the physician? & 2.1 & 11.3 & 44.8 & 25.4 & 16.5 & $3(1)$ \\
\hline 15 & In case you forget how to use any drug, do you seek the advice from the physician? & 36.3 & 24.8 & 19.8 & 16.5 & 2.7 & $2(2)$ \\
\hline 16 & In case you forget how to use any drug, do you seek the advice from the pharmacist? & 48.3 & 28.5 & 17.5 & 4.2 & 1.5 & $2(1)$ \\
\hline 17 & Do you read the leaflet in the medications' package when you forget how to use them? & 49.4 & 28.5 & 16.9 & 3.5 & 1.7 & $2(1)$ \\
\hline 18 & $\begin{array}{l}\text { In case of dispensing a previously prescribed medication, } \\
\text { do you use it in accordance with your new conditions? }\end{array}$ & 10.8 & 38.5 & 30.0 & 13.5 & 7.1 & $3(1)$ \\
\hline 19 & Upon consultation, do you tell the physician about the drugs you have been using? & 53.8 & 33.3 & 10.0 & 2.1 & 0.8 & $1(1)$ \\
\hline 20 & Upon consultation, does the physician ask you about drugs you have been using? & 48.8 & 30.8 & 15.0 & 4.6 & 0.8 & $2(1)$ \\
\hline
\end{tabular}

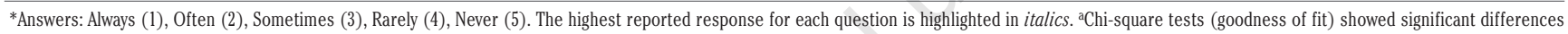
among the five possible answers to all questions $(\mathrm{P}<0.001)$. IQR, interquartile range.

Table 3. The test of independence: Chi-square and Fisher's Exact tests

\begin{tabular}{|c|c|c|c|c|c|c|c|}
\hline \multicolumn{2}{|c|}{ Questions $^{\mathrm{a}}$} & \multirow{2}{*}{$\begin{array}{c}\text { Gender }{ }^{1} \\
4.20\end{array}$} & \multirow{2}{*}{$\begin{array}{l}\mathrm{Age}^{2} \\
15.57^{*}\end{array}$} & \multirow{2}{*}{$\begin{array}{l}\text { Income }{ }^{3} \\
35.80^{*}\end{array}$} & \multirow{2}{*}{$\begin{array}{l}\text { Education }{ }^{4} \\
\text { 33.68* }\end{array}$} & \multirow{2}{*}{$\begin{array}{l}\text { Home }{ }^{5} \\
2.89\end{array}$} & \multirow{2}{*}{$\begin{array}{c}\text { Marital } \\
\text { status }^{6} \\
5.78\end{array}$} \\
\hline 1 & Have you ever avoided purchasing the prescribed medication solely due to high cost? & & & & & & \\
\hline 2 & Do you abruptly stop taking your medication earlier than prescribed? & $12.67^{*}$ & 8.94 & $18.94^{*}$ & $10.43^{*}$ & 3.12 & $9.98^{*}$ \\
\hline 3 & Do you take into consideration the exact time of administering your medications? & $13.77^{*}$ & 7.53 & $10.30^{*}$ & $12.29 *$ & 4.91 & 5.36 \\
\hline 4 & $\begin{array}{l}\text { Do you take into consideration the conditions of administering } \\
\text { a drug i.e. before/after meals? }\end{array}$ & 1.20 & 2.20 & 8.84 & $15.19^{*}$ & 4.59 & 8.47 \\
\hline 5 & Do you double the dose if you forget lor 2 doses? & $12.29 *$ & 4.05 & 7.84 & 9.14 & 2.20 & 5.94 \\
\hline 6 & Do you double the dose if you do not feel better? & 7.10 & $17.57^{*}$ & 4.23 & $11.90^{*}$ & 3.89 & $11.47^{*}$ \\
\hline 7 & Do you use any medication without consulting your physician or pharmacist? & 4.86 & 3.40 & 5.95 & $10.63^{*}$ & 0.53 & 7.10 \\
\hline 8 & Do you use others' leftover drugs? & 6.25 & 6.97 & 3.33 & $16.84^{*}$ & 7.61 & 7.48 \\
\hline 9 & Do you donate your medications if someone needs them? & 4.85 & 8.07 & 2.76 & $11.12^{*}$ & 0.99 & 1.74 \\
\hline 10 & Do you advise the others to use any drugs without medical examination? & $13.59^{*}$ & 2.06 & 5.82 & $15.25^{*}$ & 1.54 & 3.33 \\
\hline 11 & Do you continue taking a drug after its expiry date is reached? & $9.14^{*}$ & 4.16 & 4.39 & $14.40^{*}$ & 5.85 & 2.73 \\
\hline 12 & Do you continue taking a drug even if side effects occur? & 5.02 & 5.58 & 2.61 & 3.09 & 3.08 & 2.06 \\
\hline 13 & Do you have regular physical examinations if you have to use any drug for a long time? & 9.42 & $14.99 *$ & 7.58 & $10.16^{*}$ & 3.11 & $10.29 *$ \\
\hline 14 & Do you repeat purchasing a drug without consulting the physician? & $9.61^{*}$ & 1.49 & 5.19 & 9.18 & $15.68^{*}$ & 5.88 \\
\hline 15 & In case you forget how to use any drug, do you seek the advice from the physician? & 2.83 & 7.22 & 6.84 & .37 & 1.63 & 4.15 \\
\hline 16 & In case you forget how to use any drug, do you seek the advice from the pharmacist? & 1.73 & 0.69 & 4.95 & 6.69 & 1.80 & 1.61 \\
\hline 17 & Do you read the leaflet in the medications' package when you forget how to use them? & $32.73^{*}$ & $22.05^{*}$ & 6.76 & $34.59^{*}$ & 6.03 & 0.50 \\
\hline 18 & $\begin{array}{l}\text { In case of dispensing a previously prescribed medication, do you use it } \\
\text { in accordance with your new conditions? }\end{array}$ & 4.96 & $13.81^{*}$ & 4.23 & 6.50 & 4.47 & 6.77 \\
\hline 19 & Upon consultation, do you tell the physician about the drugs you have been using? & 2.70 & 0.90 & 2.69 & 1.54 & 7.70 & 2.91 \\
\hline 20 & Upon consultation, does the physician ask you about drugs you have been using? & 8.47 & $9.39 *$ & $9.81^{*}$ & 3.02 & 4.70 & 3.39 \\
\hline
\end{tabular}

${ }^{2}$ Answers on a 5 -point Likert scale (always, often, sometimes, rarely and never). ${ }^{1}$ Male and female, $\mathrm{n}=240 \mathrm{each},{ }^{2} \mathrm{n}=339$ aged less than or equal to 45 years, $\mathrm{n}=141$ aged more than 45 years, ${ }^{3} \mathrm{n}=253$ earning $\leq 240 \mathrm{Jordanian}$ dinars per month, $\mathrm{n}=227$ earning more than 240 Jordanian dinars monthly, ${ }^{\mathrm{n}} \mathrm{n}=190 \mathrm{had}$ no university education, $\mathrm{n}=290$ had one or more university degrees, ${ }^{5}$ Home $\mathrm{n}=411$ city residents, $\mathrm{n}=69$ rural areas residents, ${ }^{6} \mathrm{n}=262$ married, $\mathrm{n}=218$ unmarried. ${ }^{*} \mathrm{P}<0.05$, degree of freedom $=4$. Italicized values generated by performing the Fisher's Exact test. 
ed. The case was different when it came to pharmacists. The odds of patients with no university education was 1.46 times that of patients holding one or more university degrees in not seeking the advice from the pharmacist, indicating an important role of the university education in promoting the awareness of the role that the pharmacists play in reducing the incidence of IDU.

Lastly, the home factor had no significant impact on responses to any questions included in the survey.

\section{Discussion}

Overall, the results of this survey indicated that IDU was moderately popular in northern Jordan and emphasised that demographic and socioeconomic characteristics of outpatients significantly modified their attitudes towards medication misuse. Nevertheless, university education and earning higher salaries were, in particular, inversely proportional to the risk for not using medication appropriately. In fact, the problem of not properly using medications could also be linked to poor healthcare services although these data could have been validated in case the physi- cians or pharmacists working at selected medical centres were also enrolled in the survey. Calculating the odds ratios were found additive in analysing the relationship between responses and patients' characteristics and in determining the relative risk. ${ }^{21}$ For example respondents older than 45 years exhibited negative attitudes towards IDU like higher tendency to ignore purchasing expensive medications, to double the dose if they remained sick, and to use others' unused medications without medical examination, suggesting that more attention should be paid to senior people $(>65)$ in northern Jordan who are at high risk for potentially inappropriate drug use. As stated earlier, geriatric patients are found to be more vulnerable to IDU and therefore over the past 25 years, standard regulations have been developed to control the use of high risky drugs. For example, Beers' criteria have been established as a list of certain drugs which has recently been updated to evaluate and regulate their use/recommended dosage in the elderly. ${ }^{11,12,22}$

Obviously, the findings clearly determined an association between no university education or reduced income and the increased incidence of IDU. Indeed, it should be pointed that poor patients were at high risk for IDU by avoiding the purchase of expensive drugs, raising the need for efficient health insurance system to ensure no breach to healthcare services. Less educated par-

Table 4. Ordinal logistic regression models: odds ratios and confidence intervals.

\begin{tabular}{|c|c|c|c|c|c|c|}
\hline Questions ${ }^{\mathrm{a}}$ & $\begin{array}{l}\text { Male, } \\
\mathrm{N}=240\end{array}$ & $\begin{array}{l}\leq 45 \text { years } \\
\mathrm{N}=339\end{array}$ & $\begin{array}{l}\leq 240 \mathrm{JD} \\
\mathrm{N}=253\end{array}$ & $\begin{array}{l}\text { No university } \\
\qquad=190\end{array}$ & $\begin{array}{l}\text { Urban Home } \\
\qquad \mathrm{N}=411\end{array}$ & $\begin{array}{l}\text { Married } \\
\mathrm{N}=262\end{array}$ \\
\hline $\begin{array}{l}\text { Have you ever avoided purchasing the prescribed } \\
\text { medication solely due to high cost? }\end{array}$ & $1.12(0.81,1.57)$ & $1.60(1.08,2.36)^{*}$ & $0.43(0.30,0.61)^{*}$ & $0.47(0.33,0.68)^{*}$ & $1.00(0.62,1.60)$ & $1.13(0.79,1.60)$ \\
\hline $\begin{array}{l}\text { Do you abruptly stop taking your medication } \\
\text { earlier than prescribed? }\end{array}$ & $1.63(1.16,2.29)^{*}$ & $0.89(0.60,1.32)$ & $0.63(0.45,0.90)^{*}$ & $0.64(0.45,0.92)^{*}$ & $1.32(0.82,2.13)$ & $1.47(1.03,2.10)^{*}$ \\
\hline $\begin{array}{l}\text { Do you take into consideration the exact time } \\
\text { of administering your medications? }\end{array}$ & $0.62(0.43,0.88)^{*}$ & $1.67(1.10,2.52)^{*}$ & $1.16(0.80,1.67)$ & $1.99(1.36,2.89)^{*}$ & $0.72(0.44,1.18)$ & $0.92(0.64,1.33)$ \\
\hline $\begin{array}{l}\text { Do you take into consideration the conditions } \\
\text { of administering a drug i.e. before/after meals? }\end{array}$ & $1.01(0.71,1.44)$ & $0.93(0.62,1.40)$ & $0.90(0.62,1.30)$ & $2.12(1.45,3.08)^{*}$ & $0.73(0.45,1.20)$ & $0.61(0.42,0.89)^{*}$ \\
\hline Do you double the dose if you forget lor 2 doses? & $0.82(0.59,1.15)$ & $1.38(0.94,2.05)$ & $1.10(0.77,1.56)$ & $0.62(0.44,0.89)^{*}$ & $1.01(0.63,1.62)$ & $1.68(1.17,2.39)^{*}$ \\
\hline Do you double the dose if you do not feel better? & $0.89(0.64,1.25)$ & $1.94(1.31,2.88)^{*}$ & $0.99(0.70,1.40)$ & $0.66(0.46,0.94)^{*}$ & $1.34(0.83,2.15)$ & $1.93(1.35,2.75)^{*}$ \\
\hline $\begin{array}{l}\text { Do you use any medication without consulting your } \\
\text { physician or pharmacist? }\end{array}$ & $1.16(0.83,1.62)$ & $1.32(0.89,1.94)$ & $0.95(0.67,1.35)$ & $0.65(0.45,0.92)^{*}$ & $1.01(0.63,1.61)$ & $1.37(0.96,1.95)$ \\
\hline Do you use others' leftover drugs? & $0.87(0.63,1.22)$ & $1.51(1.02,2.22)^{*}$ & $1.19(0.84,1.68)$ & $0.55(0.38,0.78)^{*}$ & $1.21(0.75,1.93)$ & $1.56(1.09,2.22)^{*}$ \\
\hline Do you donate your medications if someone needs them? & $1.31(0.94,1.82)$ & $1.11(0.76,1.64)$ & $0.97(0.69,1.37)$ & $0.60(0.42,0.85)^{*}$ & $1.06(0.66,1.69)$ & $1.08(0.76,1.53)$ \\
\hline $\begin{array}{l}\text { Do you advise the others to use any drugs } \\
\text { without medical examination? }\end{array}$ & $1.72(1.23,2.41)^{*}$ & $0.93(0.63,1.37)$ & $0.83(0.59,1.18)$ & $0.77(0.54,1.10)$ & $0.86(0.53,1.38)$ & $0.84(0.59,1.19)$ \\
\hline Do you continue taking a drug after its expiry date is reached? & $0.56(0.36,0.86)^{*}$ & $0.93(0.57,1.53)$ & $0.77(0.49,1.20)$ & $0.55(0.35,0.85)^{*}$ & $1.49(0.84,2.62)$ & $1.32(0.84,2.07)$ \\
\hline Do you continue taking a drug even if side effects occur? & $0.86(0.61,1.20)$ & $1.29(0.87,1.91)$ & $1.32(0.93,1.88)$ & $0.81(0.57,1.16)$ & $1.26(0.78,2.04)$ & $1.46(1.02,2.09)^{*}$ \\
\hline $\begin{array}{l}\text { Do you have regular physical examinations if you have } \\
\text { to use any drug for a long time? }\end{array}$ & $0.75(0.54,1.04)$ & $1.55(1.05,2.27)^{*}$ & $1.30(0.92,1.84)$ & $1.44(1.02,2.04)^{*}$ & $0.71(0.45,1.13)$ & $1.53(1.08,2.17)^{*}$ \\
\hline Do you repeat purchasing a drug without consulting the physician? & $0.99(0.71,1.38)$ & $1.34(0.90,1.98)$ & $1.34(0.94,1.90)$ & $1.05(0.74,1.50)$ & $0.93(0.58,1.50)$ & $1.57(1.10,2.25)^{*}$ \\
\hline $\begin{array}{l}\text { In case you forget how to use any drug, do you seek } \\
\text { the advice from the physician? }\end{array}$ & $0.84(0.61,1.17)$ & $0.75(0.51,1.10)$ & $1.41(0.99,1.99)$ & $1.16(0.82,1.65)$ & $0.86(0.54,1.37)$ & $1.24(0.88,1.76)$ \\
\hline $\begin{array}{l}\text { In case you forget how to use any drug, do you seek } \\
\text { the advice from the pharmacist? }\end{array}$ & $1.13(0.80,1.59)$ & $1.08(0.72,1.60)$ & $1.30(0.91,1.86)$ & $1.46(1.02,2.10)^{*}$ & $1.05(0.64,1.70)$ & $1.20(0.84,1.73)$ \\
\hline $\begin{array}{l}\text { Do you read the leaflet in the medications' package } \\
\text { when you forget how to use them? }\end{array}$ & $2.46(1.72,3.51)^{*}$ & $0.71(0.48,1.06)$ & $1.31(0.91,1.89)$ & $1.88(1.30,2.71)^{*}$ & $0.74(0.45,1.20)$ & $0.90(0.62,1.30)$ \\
\hline $\begin{array}{l}\text { In case of dispensing a previously prescribed medication, } \\
\text { do you use it in accordance with your new conditions? }\end{array}$ & $0.99(0.71,1.38)$ & $1.06(0.72,1.56)$ & $0.83(0.58,1.17)$ & $1.12(0.79,1.59)$ & $1.34(0.84,2.16)$ & $0.70(0.49,1.00)^{*}$ \\
\hline $\begin{array}{l}\text { Upon consultation, do you tell the physician about } \\
\text { the drugs you have been using? }\end{array}$ & $0.89(0.62,1.26)$ & $1.02(0.68,1.54)$ & $0.92(0.64,1.34)$ & $1.22(0.84,1.77)$ & $0.69(0.42,1.12)$ & $0.82(0.57,1.19)$ \\
\hline $\begin{array}{l}\text { Upon consultation, does the physician ask you } \\
\text { about drugs you have been using? }\end{array}$ & $0.78(0.55,1.10)$ & $2.06(1.36,3.12)^{*}$ & $1.60(1.11,2.30)^{*}$ & $1.39(0.96,2.00)$ & $0.79(0.49,1.29)$ & $1.48(1.03,2.14)^{*}$ \\
\hline
\end{tabular}

aAnswers on a 5-point Likert scale (dependent variables: always (1), often (2), sometimes (3), rarely (4) and never (5), set as a reference) were analysed using the ordinal logistic regression model, odds ratios in italics and confidence intervals (95\%) in brackets were calculated to investigate the impact of demographic and socioeconomic characteristics of outpatients on their responses to the questionnaire. Independent variables (characteristics) were two levels each. ${ }^{*} P<0.05$, JD $=$ Jordanian dinar. 
ticipants exhibited higher tendency to use drugs inappropriately, such as reduced motivation to read the instructions in order to remember how to use the medications correctly, and to continue taking their medications until the last dose. These findings were in agreement with a previous Italian report, although at much lower incidence rates, focusing on the misuse of antibiotics. ${ }^{14}$ It has been widely reported that the educational level of patients could influence IDU in general and was found to probably underscore polypharmacy in less-educated elderly. ${ }^{23}$ This may emphasise the importance of setting new policies, undertaking training programs for healthcare professionals and running up IDU awareness raising campaigns directed mainly towards outpatients. It should be noted that $60.42 \%$ of participants were university graduates, and the reason for this could be that a teaching university hospital was one of three health service providers being involved in this study, and therefore it would be expected that a high number of outpatients were postgraduate students or academic staff. It has been reported that the most commonly and inappropriately used drugs include mainly antibiotics, ${ }^{14,24}$ as well as analgesics, antidepressants and anticholinergic drugs especially in the elderly. ${ }^{12}$ IDU does have morbidity and mortality consequences ${ }^{1}$ and is associated with increased rates of adverse drug reactions ${ }^{25-27}$ and increased bacterial resistance. ${ }^{28}$ Apart from healthy issues of medications misuse, IDU has been found to be associated with increased expenditure especially in polypharmacy patients. ${ }^{29,30}$ Repeated hospitalization linked to IDU $^{31-33}$ could represent a financial burden for the national health insurance system..$^{29,34}$ However, decreasing the incidence of IDU has been associated with improvement in patient care and limited loss of resources. ${ }^{35,36}$

The majority of patients were resident in urban areas and this could be due to the location of participating medical centres in Irbid, the second largest cosmopolitan city after Amman in Jordan. Nevertheless, there was no significant impact on patients' responses residing in rural or urban areas except that the chi-square test of independence showed a significant association between home and re-dispensing a prescribed medication without consulting the physician, and this could be due to the fact that some participants were residing in village away from Irbid or Amman where the number of medical centres and hospitals is considerably higher Although questionnaire based studies represent an important source of information in scientific research, it is widely agreed that the influence of cross section studies is to some extent limited as the responses could probably be slightly biased by participants who completed the questionnaire only once. ${ }^{37}$ In addition, although the questionnaire was presented to patients in Arabic language before being (the completed ones) translated into English, there would still be a probability that some questions may be misunderstood. However, certain measures were undertaken to overcome such limitations including prior interviews with participants, validation of the questionnaire structure, the duration of the study, population characteristics and size, and thorough analysis of the collected responses, which all could contribute to adjusting any possible confounding effects. ${ }^{7,38}$

\section{Conclusions}

This survey suggests that medication misuse is a serious issue among outpatients in northern Jordan and the attitude towards the problem of inappropriate drug use is different based on the demographic and socioeconomic characteristics of patients. The need for an effective health insurance system and promoting university education are suggested to decrease the incidence of IDU in north- ern Jordan. It also seems essential to highlight the increasing demand for more mass media IDU-awareness campaigns ${ }^{39}$ and training programmes in an attempt to make impact of IDU on healthcare services under control.

Correspondence: Mohamed Elsaed Ebada, National Organization for Drug Control and Research (NODCAR), 51 Wezaret El-Zeraa Street, Agouza, 12654 Giza, Egypt.

Tel.: +20.1069637558 .

E-mail: drmohamedebada36@gmail.com

Key words: Drug misuse; questionnaire; Likert; attitude; Jordan.

Acknowledgements: the authors would thank the interviews conducting staff and all outpatients who completed the questionnaire at Areen Medical Center, Dahiyat Al-Hussein Health Center and Princess Basma Teaching Hospital in Irbid, Jordan.

Contributions: $\mathrm{MH}$, designing and validating the questionnaire, supervising the interviewers who assisted the patients to fill the questionnaire completely and accurately, collecting the data, analysing and presenting the data in tables, writing the manuscript and approving it for submission; MEE, designing the questionnaire, confirming its validation, analysing and presenting the data in tables, co-writing the manuscript and approving its content for submission.

Conflict of interest: the authors declare no potential conflict of interest.

Received for publication: 13 February 2017.

Accepted for publication: 12 April 2017.

CC Copyright M. Haddad and M.E. Ebada, 2017

Licensee PAGEPress, Italy

Journal of Public Health Research 2017;6:818

doi:10.4081/jphr.2017.818

This work is licensed under a Creative Commons Attribution NonCommercial 4.0 License (CC BY-NC 4.0).

\section{References}

1. Samuelsson KS, Egenvall M, Klarin I, et al. Inappropriate drug use in elderly patients is associated with prolonged hospital stay and increased postoperative mortality after colorectal cancer surgery: a population-based study. Color Dis 2015;18:15562.

2. Schoenenberger AW, Stuck AE. Inappropriate drug use among older persons: is it time for action? Age Ageing 2014;43:7379 .

3. Wazaify M, Hughes CM, McElnay JC. The implementation of a harm minimisation model for the identification and treatment of over-the-counter drug misuse and abuse in community pharmacies in Northern Ireland. Patient Educ Couns 2006;64:13641.

4. Artz MB, Harnack LJ, Duval SJ, et al. Use of nonprescription medications for perceived cardiovascular health. Am J Prev Med 2006;30:78-81.

5. Blalock SJ, Byrd JE, Hansen RA, et al. Factors associated with potentially inappropriate drug utilization in a sample of rural community-dwelling older adults. Am J Geriatr Pharmacother 2005;3:168-79.

6. Gallagher P, Barry P, O'Mahony D. Inappropriate prescribing in the elderly. J Clin Pharm Ther 2007;32:113-21.

7. Mitsi G, Jelastopulu E, Basiaris H, et al. Patterns of antibiotic use among adults and parents in the community: a questionnaire-based survey in a Greek urban population. Int J Antimicrob Agents 2005;25:439-43. 
8. Skoldunger A, Fastbom J, Wimo A, et al. Impact of inappropriate drug use on hospitalizations, mortality, and costs in older persons and persons with dementia: findings from the SNAC study. Drugs Aging 2015;32:671-8.

9. Fastbom J, Johnell K. National indicators for quality of drug therapy in older persons: the Swedish experience from the first 10 years. Drugs Aging 2015;32:189-99.

10. Baldoni Ade O, Ayres LR, Martinez EZ, et al. Factors associated with potentially inappropriate medications use by the elderly according to Beers criteria 2003 and 2012. Int J Clin Pharm 2014;36:316-24.

11. Beers MH. Explicit criteria for determining potentially inappropriate medication use by the elderly. An update. Arch Intern Med 1997;157:1531-6.

12. American Geriatrics Society. 2015 Updated Beers Criteria for Potentially Inappropriate Medication Use in Older Adults. J Am Geriatr Soc 2015;63:2227-46.

13. Al-Azzam SI, Alzoubi KH, Mhaidat NM, et al. Preoperative antibiotic prophylaxis practice and guideline adherence in Jordan: a multi-centre study in Jordanian hospitals. J Infect Dev Ctries 2012;6:715-20.

14. Grosso G, Marventano S, Ferranti R, Mistretta A. Pattern of antibiotic use in the community: nuon-adherence and self-prescription rates in an Italian urban population. Mol Med Rep 2012;5:1305-10.

15. Shehadeh M, Suaifan G, Darwish RM, et al. Knowledge, attitudes and behavior regarding antibiotics use and misuse among adults in the community of Jordan. A pilot study. Saudi Pharm J 2012;20:125-33.

16. Hovstadius B, Petersson G, Hellstrom L, Ericson L. Trends in inappropriate drug therapy prescription in the elderly in Sweden from 2006 to 2013: assessment using national indicators. Drugs Aging 2014;31:379-86.

17. Napolitano F, Izzo MT, Di Giuseppe G, Angelillo IF. Public knowledge, attitudes, and experience regarding the use of antibiotics in Italy. PLoS One 2013;8:e84177.

18. Diji AK, Bam V, Asante E, et al. Challenges and predictors of exclusive breastfeeding among mothers attending the child welfare clinic at a regional hospital in Ghana: a descriptive cross-sectional study. Int Breastfeed J 2017;12:13.

19. Soleymani F, Ahmadizar F, Meysamie A, Abdollahi M. A survey on the factors influencing the pattern of medicine's use: Concerns on irrational use of drugs. J Res Pharm Pr 2017;2:5963.

20. Jamieson S. Likert scales: how to (ab)use them. Med Educ 2004;38:1217-8.

21. Rothman KJ, Lanes S, Sacks ST. The reporting odds ratio and its advantages over the proportional reporting ratio. Pharmacoepidemiol Drug Saf 2004;13:519-23.

22. MH B, JG O, Rollingher I, et al. Explicit criteria for determining inappropriate medication use in nursing home residents. Arch Intern Med 1991;151:1825-32.

23. Haider SI, Johnell K, Weitoft GR, et al. The influence of educational level on polypharmacy and inappropriate drug use: a register-based study of more than 600,000 older people. J Am Geriatr Soc 2009;57:62-9.

24. Ocan M, Obuku EA, Bwanga F, et al. Household antimicrobial self-medication: a systematic review and meta-analysis of the burden, risk factors and outcomes in developing countries. BMC Public Health 2015;15:742.

25. Laroche ML, Charmes JP, Nouaille Y, et al. Is inappropriate medication use a major cause of adverse drug reactions in the elderly? Br J Clin Pharmacol 2007;63:177-86.

26. Passarelli MC, Jacob-Filho W, Figueras A. Adverse drug reactions in an elderly hospitalised population: inappropriate prescription is a leading cause. Drugs Aging 2005;22:767-77.

27. Midlov P. Age-related disorders: pharmacokinetics and pharmacodynamics in the elderly. OA Elder Med 2013;1:1.

28. Canton R, Horcajada JP, Oliver A, et al. Inappropriate use of antibiotics in hospitals: the complex relationship between antibiotic use and antimicrobial resistance. Enferm Infecc Microbiol Clin 2013;31:3-11.

29. Bjerre LM, Ramsay T, Cahir C, et al. Assessing potentially inappropriate prescribing (PIP) and predicting patient outcomes in Ontario's older population: a population-based cohort study applying subsets of the STOPP/START and Beers' criteria in large health administrative databases. BMJ Open 2015;5:e010146.

30. Saastamoinen LK, Verho J. Register-based indicators for potentially inappropriate medication in high-cost patients with excessive polypharmacy. Pharmacoepidemiol Drug Saf 2015;24:610-8. 5

31. Dedhiya SD, Hancock E, Craig BA, et al. Incident use and outcomes associated with potentially inappropriate medication use in older adults. Am J Geriatr Pharmacother 2010;8:562-70.

32. Price SD, Holman CD, Sanfilippo FM, Emery JD. Association between potentially inappropriate medications from the Beers criteria and the risk of unplanned hospitalization in elderly patients. Ann Pharmacother 2014;48:6-16.

33. Ruggiero C, Dell'Aquila G, Gasperini B, et al. Potentially inappropriate drug prescriptions and risk of hospitalization among older, Italian, nursing home residents: the ULISSE project. Drugs Aging 2010;27:747-58.

34. Fillenbaum GG, Hanlon JT, Landerman LR, et al. Impact of inappropriate drug use on health services utilization among representative older community-dwelling residents. Am J Geriatr Pharmacother 2004;2:92-101.

35. Thompson Coon J, Abbott R, Rogers M, et al. Interventions to reduce inappropriate prescribing of antipsychotic medications in people with dementia resident in care homes: a systematic review. J Am Med Dir Assoc 2014;15:706-18.

36. Kaur S, Mitchell G, Vitetta L, Roberts MS. Interventions that can reduce inappropriate prescribing in the elderly: a systematic review. Drugs Aging 2009;26:1013-28.

37. Levin KA. Study design III: cross-sectional studies. Evid Based Dent 2006; 7:24-5.

38. Schmidt ME, Steindorf K. Statistical methods for the validation of questionnaires: discrepancy between theory and practice. Methods Inf Med 2006;45:409-13.

39. Wakefield MA, Loken B, Hornik RC. Use of mass media campaigns to change health behaviour. Lancet 2010;376:1261-71. 